\title{
Digitalk: An Exploration of the Linguistic Features of $\mathrm{CMC}$
}

\author{
Chenee M. Dino and Leah E. Gustilo
}

\begin{abstract}
This pilot study was anchored on the viewpoint that language users are creative and innovative, and that Electronic English is an emerging variety of language. This study investigates the features and functions of electronic language used by Filipino Facebook users. Results of the pilot analysis of 1,671 Facebook statuses revealed that Filipino Facebookers used nine types of linguistic features. Of these nine linguistic features, code switching and acronym are the most frequently used. The linguistic features in this study show Filipino Facebookers' competence to make use of their linguistic knowledge in order to develop innovations in communication.
\end{abstract}

Index Terms-Electronic language variety, internet English, linguistic features, digital.

\section{INTRODUCTION}

Communication and interaction nowadays have gone beyond the usual face-to-face communication; consequently, the advent of technology opened another avenue for growth of language. References [1]-[3] discussed that social networking sites (SNS) have become the quintessential places for people to meet virtually and communicate with the aid of technology. As the language of the virtual world becomes recognized, various reviews and studies have started naming its users' expressions. One term that is used to refer to internet language is Digitalk. Digitalk is regarded as a new way to communicate in the digital setting, which evidently shows manipulation in the spellings and conventions that occur when people communicate with each other [4]. Digitalk, having its own conventions, was observed to be 'nonstandard' but is given enough attention in the cyber world. Although many have viewed Digitalk as an interesting way to communicate over the net, it can pose threat to communicators as they may have trouble switching from digital language to standard English [4].

However, despite the negative views about Digitalk, Internet English continuously penetrates not only the social networking sites but ordinary conversations as well. For example, Photobomb and Selfie are words that rose from SNS, and their popularity has been brought beyond the virtual world to the extent that they were carried even to the real world. It is now evident that people have started using virtual-borne words in traditional face-to-face communication, which justifies the need for investigating the new forms found in the internet.

Reference [5] conducted an exploratory study on Computer-mediated communication focusing on Social

Manuscript received August 19, 2014; revised February 12, 2015.

The authors are with the De la Salle University, Manila, Philippines (email: leah.gustilo@dlsu.edu.ph).
Networking Sites (SNS) such as Facebook and Twitter. Reference [5] claimed that although Facebook and other SNS have been regarded as a vital part of college students' lives, it was named as a boon and a bane in higher education [5]. Reference [6] revealed that some educators find Facebook useful in school but may be distracting to students. It is therefore necessary that teachers become eyewitnesses in the way students use CMC.

Reference [7] attempted to study the multi-features and forms in the Internet communication. The study focused on the analysis of several forms of media and identified the features and functions of the internet language of Malaysian speakers. From the observation, the authors concluded that Malaysian electronic communication is an emerging language variety with its features and functions. The new variety of language was evident in informal communication via Electronic media such as blogs, chats or instant messages, e-mails and text messages. The analysis revealed that Malaysian online communication has features such as code-switching and code-mixing, abbreviations and acronyms, discourse particles, borrowings, affixation, coinage and blending. Moreover, the varieties serve the purpose of affirming the participants involved in the conversation [7].

As SNS becomes a new world or society, much attention has been given to it by writers ranging from linguistic features to pragmatic functions. Focusing on the pragmatics of CMC, [8] constructed a self-made gratification scale to measure the level of gratification that the CMC participants receive in SNS. Gratification was operationally defined as the use of $\mathrm{CMC}$, and its levels are diversion, personal identity, interpersonal relationship, and exchange of information. Results of their study revealed that participants use CMC for gratifying their interpersonal relationship needs. Moreover, among the types of CMC that participants use, SNS is the most gratifying because participants found the features complete which include chatting, the use of images, and others. This then leads to one feature of CMC which is multimodality. Reference [9] stated that in online texts, meaning is brought by various modes such as pictures and photo albums. The multimodality of SNS allows the Internet users to explore meanings and even add to existing ones; hence, Internet users also develop the skills to making meaning in online communication.

References [10] and [11] stated that there are 33.6 million active internet users in the Philippines during year 2013. The demography comprises $40 \%$ of users who are ages 15 $24 ; 31 \%$ are between ages $25-34 ; 16 \%$ are between ages 35 44 and $9 \%$ are between ages $45-54$ and $5 \%$ are ages 55 and above. Reference [11] added that the ages of most Internet users in Southeast Asia are 35 and below. Specifically, 
Philippines comprises $71 \%$ of Internet audience who are between 15 and 34. Moreover, [10] claimed that Filipinos spend an average of 16.4 hours on the internet in which $41.5 \%$ is devoted to social media; $17.3 \%$ on services; and $14.5 \%$ on news and information. With new technologies available, $40 \%$ of Filipino smartphone owners browse the internet using their mobile device. In addition, $50 \%$ of Filipino Internet users access blogs, with an average of 14.4 minutes spent on each visit [10].

Philippines, together with Thailand and Malaysia, is included among Top 15 countries with the highest Facebook penetration globally [11]. The list seemed to intensify the recognition by Southeast Asia Digital Future in Focus 2013 that Philippines was the fastest growing Internet audience in Southeast Asia. In relation to the significance of Internet to Filipinos' lives, it was reported that around the world, Filipinos constitute $17 \%$ of web users who visit social networking sites; $5 \%$ multimedia sites; $3 \%$ photo sharing sites; $5 \%$ entertainment sites; $3 \%$ search engine sites; and $1 \%$ gaming sites [10].

With the information stated above, it is of great interest to investigate the Filipino Internet users' language. Specifically, this study attempts to answer the following questions:

1) What are the prevalent linguistic features evident in the language of Filipino Netspeakers?

2) What functions are played by the features of the Filipino Netspeakers' electronic language variety?

3) Why do Filipino Netspeakers use the electronic language variety in Computer-mediated communication?

\section{Methodology}

The present study reports the findings of the pilot analysis of Filipino internet language involving20 college students who are 10 females and 10 males with ages ranging from 15 to 24. The subjects update their FB statuses regularly, at least once every week, and they all have updated their statuses more than 50 times since they became a FB member. Although the status updates were posted publicly, we sought the permission of the Facebookers before accessing the data.

Using the Status Compiler Application of Facebook, 1,671 status updates were collected from the respondents. The status updates that were included date from August 2012 to August 2013. After gathering a number of expressions from FB, the answers were analyzed according to the features of electronic English [7].

Reference [7] identified eight features of electronic English, and they are the bases of our analysis of the Electronic language variety. Code-switching and codemixing are marked by the use of two or more languages interchangeably. Abbreviation and acronym are characterized by shortening of lexical items for brevity. The third feature, discourse particle, comprises short expressions which replace the functions represented by grammar and intonation in oral discourse. Borrowing appears when no specific counterpart is found in one language. The next feature, blending, is a word produced by combining parts of more than two words. Lastly, compounding is marked by the combination of words to form a new word with a new meaning.

The respondents were surveyed as to the reasons why they use their language in the internet. In addition, they were asked to give the electronic language counterpart of some English expressions and list down the common linguistic expressions they use in Facebook. Some of the expressions included in the survey were taken from studieson CMC by [12].

\section{Discussion}

Using a framework for analyzing Electronic English, our analysis reveals that the most prevalent linguistic feature was the use of acronym. There were also abbreviations, discourse particles, borrowing, affixation, compounding, blending, and code-switching [7] in the status updates of the Facebookers. These are graphically presented in Table I

Table I shows the nine features of Filipino internet language that were evident in the status updates of the Facebookers in this study. The features include Abbreviation (F1), Acronym (F2), Discourse Particles (F3), Borrowing (F4), Affixation (F5), Compounding (F6), Blending (F7), and the last, Code-switching (CS), which was classified into Inter-sentential (F8) and Intra-sentential (F9). Intra-sentential CS, Inter-sentential CS, and Acronym are the most frequently used features.

Nearly half of the total number of identified linguistic features is Intra-sentential Code-switching, making Intrasentential Code-switching the most prevalent linguistic feature in the status updates of the Filipino Facebookers in this study. Moreover, Inter-sentential code-switching ranked third in the list with nearly one hundred occurrences (11\%). The findings of this pilot study seem to corroborate a study on Filipino Electronic mail communication wherein code switching was also found to be evident [13]. Reference [13] identified several instances of Intra-sentential and Intersentential CS, establishing that Code-switching is a predominant characteristic of electronic communication.

There were a little above one hundred instances (18\%) of Acronyms in the status updates of the Facebookers in this study, making the said linguistic feature ranked second in the list. The expressions OMG (Oh my God), OTW (On the way) and Laugh out loud (LOL) were some of the popular acronyms used by the Facebookers. Yule's (1996) Wordformation Processes explained that the occurrences of acronym in Electronic communication are due to the language users' ability to form new words. This ability is further explained by the inherent characteristic of language users which is creativity [14].

In relation to the second research question, the linguistic features found on the status updates of the Filipino Facebookers revealed various functions. The Filipino Facebookers used Abbreviation to express strong emotion aside from shortening their expressions. Acronyms were used to shorten the expression so that the Filipino Facebookers can provide a simple update about themselves. Discourse particles were used to provide emphasis to the statement that follows. The Filipino Facebookers tend to use Discourse particles to introduce their status update. It was also revealed that Filipino Facebookers borrowed items that belong to the technical vocabulary. Moreover, the status 
updates showed that Affixation tends to provide local color to the English expression. Compounding was found in the status updates of Filipino Facebookers who put together two words to create a "new" term that covers the essence or meaning of the combined words. It seems that the
Facebookers used this as a strategy to shorten expressions. Blending seems to make the Facebookers appear stylish. Lastly, Code-switching enabled the Filipino Facebookers to post status updates with ease based on the language that they prefer to use.

\begin{tabular}{|c|c|c|c|c|c|c|c|c|c|c|}
\hline & $* \mathbf{L F 1}$ & LF2 & LF3 & LF4 & LF5 & LF6 & LF7 & LF8 & LF9 & Total \\
\hline **M1 & 2 & 6 & & & 2 & & 1 & 1 & & 12 \\
\hline M2 & & 11 & 1 & & 3 & & & 6 & 15 & 36 \\
\hline M3 & & 2 & & & & & & 4 & 9 & 15 \\
\hline M4 & 2 & 1 & 3 & & & 1 & 5 & 2 & 16 & 30 \\
\hline M5 & 3 & 6 & & 1 & 1 & & & 3 & 14 & 28 \\
\hline M6 & & 5 & & 3 & 2 & 2 & 1 & & 3 & 16 \\
\hline M7 & 3 & 3 & 2 & & 1 & & & & 7 & 16 \\
\hline M8 & & 4 & & & 1 & & & 2 & 4 & 11 \\
\hline M9 & 2 & 18 & 3 & 6 & 5 & & & 3 & 21 & 58 \\
\hline M10 & & & 1 & 3 & 7 & & & & 21 & 32 \\
\hline$* * * \mathbf{F 1}$ & 2 & 9 & 1 & 7 & 6 & & & 6 & 26 & 57 \\
\hline F2 & 6 & 9 & 4 & 6 & & & & 11 & 50 & 86 \\
\hline F3 & 4 & 8 & & 2 & 2 & & & 4 & 10 & 30 \\
\hline F4 & 2 & 7 & & & & & & 1 & 6 & 16 \\
\hline F5 & 1 & & & & & 1 & & 5 & 4 & 11 \\
\hline F6 & 1 & 5 & & & 1 & 3 & & 2 & 20 & 32 \\
\hline F7 & 1 & 2 & & 5 & & & & 5 & 22 & 35 \\
\hline F8 & 1 & 10 & 2 & & & 3 & & 2 & 5 & 23 \\
\hline F9 & 2 & 6 & 2 & 12 & 9 & & & 9 & 34 & 74 \\
\hline F10 & & 4 & 3 & & 2 & & & 7 & 13 & 29 \\
\hline TOTAL & 32 & 116 & 22 & 39 & 48 & 10 & 7 & 73 & 300 & 647 \\
\hline
\end{tabular}

This study aimed at investigating why Filipino Facebookers use the English electronic variety in Computermediated communication. According to the respondents, they use acronym because it is more convenient to use. On the use of code-switching, some mentioned that code switching enables them to express what they really mean. Some respondents reported that they use code-switching because it is more understandable to their readers. Others reasoned out that they use this feature because their readers use the same linguistic feature. They revealed as well that code switching is used for lack of words and stylistic purposes. Filipino Facebookers stated that they use shortened words when communicating using ICT because they save space, time of encoding, and because they got used to them. Emoticons were used by the respondents because they amplify their feelings, virtually represent gestures, provide emphasis, deploy humor, give orders and ask favors. The respondents seem to have an evident degree of familiarity in the practice of using the Electronic language variety in the ICT.

In addition, the respondents were asked to list down the common linguistic expressions they use in Facebook. Some of the expressions they listed were brb (be right back), pls (please), and mornyt (good morning+night). In the ICT, symbols seem to contain their own meaning since there were respondents who identified the use of [?] and [:)] to graphically represent the expression "why" and express a favorable emotion like happiness. In addition, we prepared a total of twenty-five expressions and asked the five respondents to provide the internet or electronic language counterparts of the expressions enumerated in the survey questionnaire. The respondents' (represented by the labels R1-R5) answers are shown in Table II.

Table II shows that the respondents have different and similar ways to express themselves in ICT. As shown by the listed electronic language expressions, the respondents tend to employ a variety of features such as acronym, shortenings and use of symbols. The respondents took the liberty in choosing between the original English expression and their electronic language variety depending on their preference. It is also evident in the list that some respondents demonstrated the use of the standard English spelling of words, while others have their unique version of the English expressions.

Findings of this pilot study revealed the feasibility of conducting linguistic analysis on the language of the Internet. The linguistic features in this study show Filipino Facebookers' competence in making use of their linguistic knowledge in order to develop innovations in communication. In addition, Filipino Facebookers' English 
electronic variety shows similarities with the Malaysian English Electronic variety. However, due to the restrictions imposed on our data, generalizations cannot be made regarding the features of Filipino internet English. Hence, we recommend that a study involving larger sample of Filipino Facebookers or other SNS be made. Furthermore, an analysis using intercultural rhetoric framework be made in order to investigate the cross-cultural differences and similarities in electronic communication.It would also be of great interest to conduct a follow-up investigation involving a reverse method in the linguistic survey to find out whether the internet users can identify the English expression counterparts of the Electronic language expressions.

TABLE II: RESPONDENTS’ ELECTRONIC LANGUAGE EXPRESSIONS

\begin{tabular}{|c|c|c|c|c|c|c|}
\hline \multicolumn{2}{|r|}{ Expressions } & \multirow{2}{*}{$\begin{array}{l}\text { R1 } \\
\text { gud mrng }\end{array}$} & \multirow{2}{*}{$\begin{array}{c}\text { R2 } \\
\text { Gud morning }\end{array}$} & \multirow[t]{2}{*}{ R3 } & $\mathrm{R} 4$ & \multirow[b]{2}{*}{ gud am } \\
\hline 1. & good morning & & & & Gudam & \\
\hline 2. & by the way & by d way & By d way & Btw & Btw & Bdw \\
\hline 3. & before & $\mathrm{b} 4$ & B4 & Before & b4 & b4 \\
\hline 4. & you & $\mathrm{U}$ & $\mathrm{U}$ & $\mathrm{U}$ & $\mathrm{U}$ & $\mathrm{U}$ \\
\hline 5. & as soon as possible & Asap & Asap & Asap & Asap & Asap \\
\hline 6. & because & $\mathrm{Bcoz}$ & Bcause & $\mathrm{Bcoz}$ & $\mathrm{Bec}$ & $\mathrm{Bcoz}$ \\
\hline 7. & what & Wat & What & Wat & Wat & $?$ \\
\hline 8. & together & Together & 2 gether & Tgether & Together & 2gther \\
\hline 9. & tomorrow & Tmrw & 2 morow & Tom & Tom & 2 moro \\
\hline 10. & see you later & see $u$ latr & $\mathrm{Cu}$ later & cu later & cu later & $\mathrm{c} \mathrm{u} 18 \mathrm{r}$ \\
\hline & me too & me too & M 2 & me too & me 2 & me 2 \\
\hline 12. & I am sorry & I am sorry & I'm sorry & Sorry & I m sorry & am sori \\
\hline 13. & Friend & frnd & Friend & Friend & Friend & Frend \\
\hline 14. & Something & somethng & Something & sumthing & Sumthng & Sumthng \\
\hline 15. & Nothing & nothing & Nothing & Nothing & Nothing & Nothng \\
\hline 16. & do not & dnt & Do not & don't & do not & dont \\
\hline & never mind & never mind & Nvr mind & never mind & nevermind & nevr mind \\
\hline & the & the/ d & $\mathrm{D}$ & don't & $\mathrm{D}$ & $\mathrm{D}$ \\
\hline 19. & happy birthday & happy birthday & Happy bday & Hbd & hapi bday & Hbd \\
\hline & good night & nytnyt & Gud nyt & Gudnyt & g'nyt & Gudnyt \\
\hline 21. & oh I see & oh I see & Oh I c & oh is ee & o I c & Oic \\
\hline 22. & thank you & thank u & Thank you & ty/ thanks & thank u & $\operatorname{Tn} x$ \\
\hline 23. & I love you & I love $\mathrm{u}$ & I love you & I love you & I love u & i luv u \\
\hline 24. & congratulations & congratulations & Congrats & Congrats & CONG-RATS! & Congrats \\
\hline & good bye & gudbye & Gud bye & Bye & g'bye & gudbye/bye \\
\hline
\end{tabular}

\section{REFERENCES}

[1] C. Ess, F. Sudweeks, and S. Herring, Culture, Technology, Communication: Towards an Intercultural Global Village, NY: SUNYP, 2001, pp. 1-11.

[2] C. Atkins, "Virtual experience: Observations on second life," in Computer-Mediated Social Networking, M. Purvis and B. Savarimuthu, Eds. Germany: Springer-Verlag Berlin Heidelberg, 2009 , pp. 7-17.

[3] S. Stoerger, "Transmedia communication: The virtual classroom experiene," in Computer-Mediated Communication: Issues and Approaches in Education, S. Kelsey and K. S. Amant, Eds. USA: IGI Global, 2012, pp. 15-32.

[4] K. Turner, "Digitalk: A new literacy for a digital generation," Kappan, vol. 92, September 2010.

[5] J. Ryan, "Meeting them halfway: Using social networking to connect with students," in Computer-Mediated Communication: Issues and Approaches in Education, S. Kelsey and K. S. Amant, Eds. USA: IGI Global, 2012, pp. 1-14.

[6] N. Selwyn, "Faceworking: Exploring stduents' education-related use of Facebook," Learning, Media and Technology, vol. 2, pp. 157-174, 2009.

[7] N. Hassan and A. Hashim, "Electronic English in Malaysia: Features and language in use," World English, vol. 30, pp. 551-568, 2011.
[8] M. Bolalin, T. Hong, and T. Yao, "Cyber stratification: A look on gratification levels across types of computer-mediated communication among Filipino undergraduate students," Undergraduate Thesis, De La Salle Univ., Manila, Philippines, 2011.

[9] J. Davies, "Discourse and computer-mediated communication," in The Continuum Companion to Discourse Analysis, K. Hyland and B. Paltridge, Eds. NY: Continuum International Publishing Group, 2011.

[10] N. Baldivia. (November 2013). The state of Philippine internet usage 2013 (Infographic.). [Online]. Available http://www.forward.ph/blog/the-state-of-philippine-internet-usage2013-infographic/

[11] K. Visconti. (August 2013). PH Internet audience growth fastest in Southeast Asia. [Online]. Available: http://www.rappler.com/life-andstyle/technology/35384-philippine-internet-audience-growthcomscore

[12] A. Bodomo, Computer-Mediated Communication for Linguistics and Literacy: Technology and Natural Language Education, USA: IGI Global, 2010, pp. 118-134.

[13] M. Bautista, "An analysis of the functions of Tagalog-English code switching: Data from one case," in The Filipino Bilingual: A Multidisciplinary Perspective (Festschrift in Honor of Emy M. Pascasio), M. Bautista and G. Tan, Eds. Manila: Linguistic Society of the Philippines, 1999, pp. 19-31.

[14] G. Yule, A Study of Language, 2nd ed. Cambridge University Press: USA, 1996, pp. 19-29. 


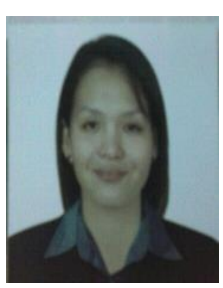

Chenee Merene Dino resides in the small town of Pagbilao, a municipality in the Province of Quezon and she was born in Valenzuela Metro, Manila on December 25, 1988. She obtained the bachelor degree of secondary education and master degree of arts in education, majoring in English, from Manuel S. Enverga University Foundation, Lucena City. She is a doctoral student in the Department of Applied Linguistics, De La Salle University, Manila.

She had taught languages and humanities subjects in the College of Arts and Sciences of Manuel S. Enverga University Foundation, Lucena City and San Sebastian College-Recoletos, Manila. She had become a faculty member in the English Department of the School of Multidisciplinary Studies of College of Saint Benilde, Manila. She is an assistant professoria lecturer in the Department of Applied Linguistics, De La Salle University, Manila, Philippines.

Ms. Dino is a member of the Linguistic Society of the Philippines. She has presented papers on Computer-mediated Communication and World Englishes. Her research interests include CMC, world Englishes, sociolinguistics and pragmatics.

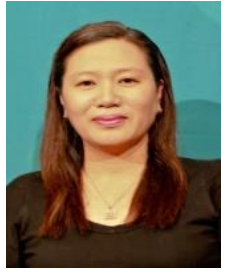

Leah Espada Gustilo is an associate professor in the Department of English Applied Linguistics, De La Salle University, Manila, Philippines,

She teaches English communication and other courses in the undergraduate and graduate programs.

Dr. Gustilo has published articles on contrastive rhetoric, Philippine English, online self-presentation, and ESL writing and assessment in reputable journals She has presented her research works in Asia and in USA. She is also actively engaged in assessment and impact evaluation projects commissioned by local and international agencies. She is an associate editor of the Philippine ESL Journal, an article editor in SAGE Open publications, and a reviewer in several international journals. 